Климов А.А., Стручков А.В. Результаты исследования влияния твердости и микроструктуры тормозных локомотивных колодок на экстремальное торможение локомотива // Вестник Пермского национального исследовательского политехнического университета. Машиностроение, материаловедение. - 2019. - Т. 21, № 1. C. $71-76$. DOI: $10.15593 / 2224-9877 / 2019.1 .10$

Klimov A.A., Struchkov A.V. The results of the study of the influence of hardness and microstructure of the locomotive brake pads for extreme braking of the locomotive. Bulletin PNRPU. Mechanical engineering, materials science, 2019, vol. 21, no. 1, pp. 71-76. DOI: 10.15593/2224-9877/2019.1.10

ВЕСТНИК ПНИПУ. Машиностроение, материаловедение T. 21, № 1, 2019

Bulletin PNRPU. Mechanical engineering, materials science http://vestnik.pstu.ru/mm/about/inf/

DOI: $10.15593 / 2224-9877 / 2019.1 .10$

УДК 629.4-592

\author{
А.А. Климов ${ }^{1}$, А.В. Стручков ${ }^{2}$ \\ ${ }^{1}$ Красноярский институт железнодорожного транспорта, фрилиал Иркутского государственного \\ университета путей сообщения, Красноярск, Россия \\ ${ }^{2}$ Сибирский государственный аэрокосмический университет им. акад. М.Ф. Решетнева, Красноярск, Россия
}

\title{
РЕЗУЛЬТАТЫ ИССЛЕДОВАНИЯ ВЛИЯНИЯ ТВЕРДОСТИ И МИКРОСТРУКТУРЫ ТОРМОЗНЫХ ЛОКОМОТИВНЫХ КОЛОДОК НА ЭКСТРЕМАЛЬНОЕ ТОРМОЖЕНИЕ ЛОКОМОТИВА
}

\begin{abstract}
Основным показателем, характеризующим эффективность применяемых мер по снижению износов локомотивных колес, является фактический ресурс бандажа локомотива, учитывающий потери металла бандажа не только при эксплуатации колесных пар, но и при их обточке, с применением ресурсосберегающей технологии. Анализ мероприятий по повышению срока службы колесных пар локомотивов на Красноярской железной дороге и их эффективности показал, что накопленный производственный опыт по увеличению срока службы колесных пар локомотивов не всегда дает положительный эффект.

В КрИЖТ ИрГУПС проведены исследования влияния микроструктуры тормозных локомотивных колодок на трибологические свойства системы колесо-колодка. В результате этих исследований была предложена экспериментальная микроструктура тормозной локомотивной колодки, состоящая из феррита и графита, которую легко и без особых затрат можно получить как в условиях заводаизготовителя, так и в условиях ремонтных предприятий. Проведены сравнительные эксплуатационные испытания.

Изложены материалы исследования влияния микроструктуры и твердости тормозных локомотивных колодок на путь экстренного торможения локомотивов. Испытания проводились на трех тепловозах грузового движения на перегонах станции Ачинск Красноярской железной дороги, оборудованных колодками трех групп: стандартных пониженной твердости, стандартных повышенной твердости и экспериментальных (со структурой феррито-графитовой). Анализ материалов исследований позволил установить, что при экстренных торможениях тепловозов со скорости до 55 км/ч путь экстренного торможения не зависит от структуры и твердости тормозных колодок. При экстренном торможении со скоростью более 55 км/ч увеличивается путь экстренного торможения тепловоза с колодками повышенной твердости и при скорости 80 км/час эта разница достигает 31 \%. При этом тормозные колодки стандартные пониженной твердости и колодки экспериментальной группы в указанном скоростном диапазоне обеспечивают совершенно одинаковый путь торможения.

Ключевые слова: путь экстренного торможения, локомотивные тормозные колодки, структура чугуна, твердость, графит, фреррит, цементит, ресурс бандажей, лубрикация, термическое упрочнение.
\end{abstract}

\author{
A.A. Klimov, A.V. Struchkov \\ ${ }^{1}$ Krasnoyarsk Institute of Railway Transport, branch of Irkutsk State Transport University, \\ Krasnoyarsk, Russian Federation \\ ${ }^{2}$ Siberian State Aerospace University named after academician M.F. Reshetnev, Krasnoyarsk, \\ Russian Federation
}

\section{THE RESULTS OF THE STUDY OF THE INFLUENCE OF HARDNESS AND MICROSTRUCTURE OF THE LOCOMOTIVE BRAKE PADS FOR EXTREME BRAKING OF THE LOCOMOTIVE}

The main measure of the effectiveness of measures to reduce wear of the locomotive wheels is the actual resource of a bandage of the locomotive, taking into account the loss of metal brace not only during operation of wheel pairs, but when they are turning, with application of resource saving technologies. Analysis of measures for increasing service life of locomotive wheel pairs on the Krasnoyarsk railway and their effectiveness showed that the accumulated production experience by increasing life of wheel pairs of locomotives does not always produce a positive effect.

In Krijt Irgups investigated the effect of the microstructure of the locomotive brake pads on the tribological properties of system "wheel pad". As a result of these studies was an experimental microstructure locomotive brake pads consisting of ferrite and graphite, which easily and inexpensively can be obtained in the conditions of the manufacturer and conditions of repair facilities and comparative performance tests. 
This paper presents the study of the influence of the microstructure and hardness of the locomotive brake pads on the way emergency braking of locomotives. The tests were carried out three locomotives freight traffic on the stretch of station Achinsk Krasnoyarsk railway equipped with the pads of three groups- standard of low hardness, high standard hardness and experimental (with the structure of ferrite-graphite) analysis of the research material allowed to set, that during emergency braking of locomotives with speeds of up to $55 \mathrm{~km} / \mathrm{h}$ the path of the emergency braking does not depend on the structure and hardness of brake pads. During emergency braking at a speed over $55 \mathrm{~km} / \mathrm{h}$ increases the way emergency braking of a locomotive with pads of high hardness and at a speed of $80 \mathrm{~km} / \mathrm{h}$, this difference reaches $31 \%$.

Keywords: the way of the emergency brake, locomotive brake pads, the structure of cast iron, hardness, graphite, ferrite, cementite, resource bandages, lubricate, thermal hardening.

\section{Введение}

Проблема ресурсообеспеченности колодочных тормозов подвижного состава и износа в трибологической паре колесо-колодка на отечественных железных дорогах всегда стояла остро. Она сохраняет свою актуальность и в настоящее время.

Данная проблема требует решения техникоэкономических, технологических, металловедческих, трибологических задач, связанных с выбором износостойких фрикционных чугунов, конструкции, оптимально приемлемой для установления на локомотив чугунных тормозных колодок при соблюдении экологически чистых технологий производства [1-6].

Локомотивными депо Красноярской железной дороги в течение десятков лет накоплен богатейший производственный опыт по увеличению срока службы колесных пар локомотивов.

Внедрение ресурсосберегающих технологий в производство позволило повысить ресурс бандажей колесных пар тягового подвижного состава в 1,5-2 раза, с 300 до 600 тыс. км.

Увеличение ресурса бандажей достигалось за счет применения комплекса технических средств.

В первую очередь это лубрикация. Смазывание боковых граней головок рельсов в кривых участках пути, подверженных интенсивному износу, осуществлялось передвижными локомотивамирельсосмазывателями, а с 2012 г. за счет сетевой программы ресурсосбережения на дорогу начали поступать вагоны-рельсосмазыватели производства $3 \mathrm{AO}$ «Фирма Твема». В настоящее время на полигоне Красноярской железной дороги установленную технологию лубрикации обеспечивают четыре собственных вагона-рельсосмазывателя, эксплуатирующиеся в составе местных поездов, главный ход Мариинск - Юрты прикрыт сетевыми вагонами-рельсосмазывателями. Кроме того, на малодеятельных участках задействованы один локомотив-рельсосмазыватель и два мобильных рельсосмазывателя на комбинированном ходу MPK-1 [7].

Во вторую очередь для снижения интенсивности износов гребней колесных пар грузовых локомотивов, которые в наибольшей степени подвержены износу, на дороге используется технология их термического упрочнения на установках
УМПУ. В настоящий момент в границах Красноярской железной дороги эксплуатируется пять установок магнитно-плазменного упрочнения колесных пар, однопостовая установка УМПУ-1 для магнитоплазменного упрочнения гребней с выкаткой колесных пар из-под локомотива [7].

Основным показателем, характеризующим эффективность применяемых мер по снижению износов локомотивных колес, является фактический ресурс бандажа локомотива, учитывающий потери металла бандажа не только при эксплуатации колесных пар, но и при их обточке с применением ресурсосберегающей технологии [1].

С учетом опыта применения ресурсосберегающей технологии при производстве обточек колесных пар решение проблемы снижения износов в контакте колесо-рельс связано с выбором оптимального профиля для обточки бандажей. Во исполнение распоряжения ОАО «РЖД» от 15.03.2004 г. № 1700p с июля 2004 г. начат переход на обточку колесных пар электровозов по профилю ДМеТИ.

Перечисленные меры по снижению износов в контакте колесо-рельс позволили снизить интенсивность износа гребней бандажей колесных пар грузовых электровозов с 1,43 мм/10 тыс. км в 1995 г. до 0,36 мм/10 тыс. км в 2016 г. В то же время анализ показателей износа бандажей колесных пар локомотивов показывает, что они стабилизировались за последние 7 лет [1]. Представляется невозможным дальнейшее снижение износов в контакте колесо-рельс существующими инструментами. Для дальнейшего роста ресурса бандажей требуется применение новых решений.

Одним из направлений дальнейшего повышения ресурса бандажей колесных пар локомотивов является оптимизация работы трибологической пары бандаж-тормозная колодка, которая, как и рельс, интенсивно изнашивает бандаж, изменяет его геометрию.

\section{Исследования}

Комплексом теоретических и экспериментальных работ, проведенных на кафедре «Эксплуатация железных дорог» Красноярского института железнодорожного транспорта, филиала Иркутского государственного университета путей сообщения в 2013-2017 гг., было выявлено [6-20], что из- 
носы бандажей колес локомотивов в условиях эксплуатации тормозными колодками за одну установку могут достигать 4 и более миллиметров. При этом следы патологического износа материала бандажей иногда наблюдаются на $20 \%$ и более тормозных колодок.

В результате проведенных исследований была предложена структура чугуна тормозной колодки [8, 11-13], которая отличается от стандартной стабильностью строения и наличием большого количества графитных включений различной консистенции. Сравнительные эксплуатационные испытания показали, что экспериментальные колодки имеют не меньший ресурс, чем стандартные, практическое отсутствие трещинообразования и следов патологического износа.

При всех положительных результатах по использованию экспериментальной структуры чугуна тормозных колодок нерешенным оставался вопрос о влиянии этой структуры на процесс торможения в экстренных ситуациях, которые сопровождаются большой продолжительностью при максимальном тормозном усилии.

С этой целью для изучения влияния структуры и твердости тормозных колодок на путь экстренного торможения в 2017 г. были проведены испытания на трех тепловозах.

Для проведения испытаний было отобрано три группы тормозных колодок по твердости: стандартной твердости низкого диапазона, стандартной твердости высокого диапазона и для отжига на структуру «феррит + графит». В таблице приведены статистические параметры твердости отобранных для испытаний тормозных колодок (более подробно в работе [7]).

В таблице коэффициент вариации, \%,

$$
\gamma=\sigma \cdot 100 / m
$$

Коэффициент неравномерности твердости на поверхности колодки, \% (по пяти замерам твердомером ТЭМП-3):

$$
v=\left(\mathrm{HB}^{\max }-\mathrm{HB}^{\mathrm{min}}\right) \cdot 100 / m .
$$

Для получения экспериментальной структуры чугуна отобранные колодки были отожжены в условиях локомотивного депо по методике, изложенной в работе [7].

Статистические параметры твердости, отобранных для испытаний тормозных колодок

\begin{tabular}{|l|c|c|c|c|}
\hline $\begin{array}{c}\text { Группа } \\
\text { колодок }\end{array}$ & $\begin{array}{c}\text { Матема- } \\
\text { ожческое } \\
\text { ние } m, \\
\text { НВ }\end{array}$ & $\begin{array}{c}\text { Средне- } \\
\text { квадра- } \\
\text { тическое } \\
\text { отклонение } \\
\sigma, \text { НВ }\end{array}$ & $\begin{array}{c}\text { Коэф- } \\
\text { фициент } \\
\text { вариации } \\
\gamma, \%\end{array}$ & $\begin{array}{c}\text { Нерав- } \\
\text { номер- } \\
\text { ность } \\
\text { средняя } \\
\text { v, \% }\end{array}$ \\
\hline Мягкие & 229 & 56,6 & 24,7 & 12 \\
\hline Твердые & 312 & 21,3 & 6,8 & 14 \\
\hline $\begin{array}{l}\text { Для } \\
\text { отжига }\end{array}$ & 275 & 29,7 & 10,8 & 17 \\
\hline $\begin{array}{l}\text { Всей } \\
\text { партии } \\
(150 \text { шт.) }\end{array}$ & 279 & 47,9 & 17,2 & 14 \\
\hline
\end{tabular}

Отобранные колодки были установлены следующим образом:

1. Группа стандартной твердости низкого диапазона на тепловозе 2ТЭ10М № 2760.

2. Группа стандартной твердости высокого диапазона на тепловозе 2ТЭ10М № 3045.

3. Экспериментальные на тепловозе 2ТЭ10М № 2758.

Экстремальное торможение производилось после примерно 50 \% износа колодок (после окончания приработки). Ход эксперимента записывался на скоростемерную ленту. Результаты проведенных испытаний показаны на рисунке.

Как видно из графиков, приведенных на рисунке, при скоростях движения от 20 до 55 км/ч интенсивность экстренного торможения для всех трех типов колодок практически одинакова (расхождение в пределах ошибки). При дальнейшем увеличении изначальной скорости торможения от 55 км/ч до 80 км/ч происходит увеличение длины тормозного пути тепловоза с твердыми колодками на $31 \%$. При этом длина тормозного пути тепловозов № 2758, 2760 составила 390 и 392 м соответственно.

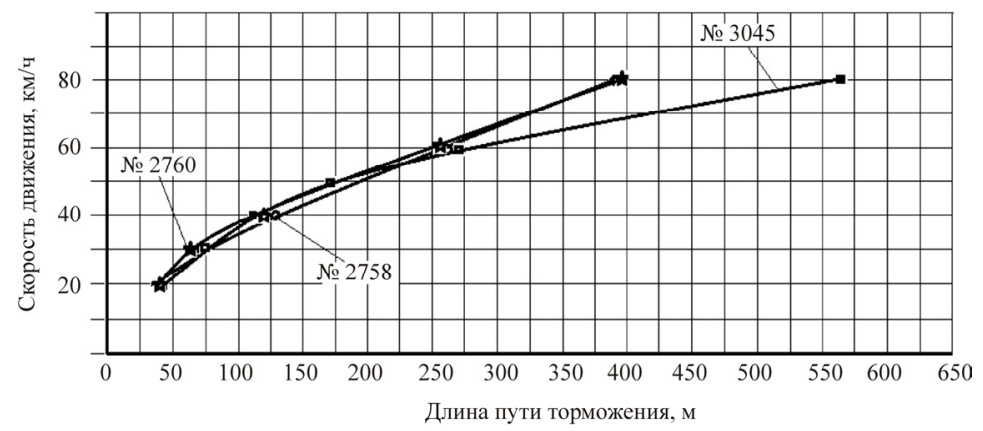

Рис. Кривые экстремального торможения при различных исходных скоростях движения 


\section{Выводы}

1. На скоростях до 55 км/ч путь экстренного торможения не зависит от твердости и структуры тормозных колодок.

2. Повышенная твердость тормозных колодок ухудшает тормозные свойства, снижая коэффициент трения, удлиняет тормозной путь экстренного торможения на скоростях выше средних.

3. В исследованном скоростном диапазоне экстренного торможения путь торможения для экспериментальных колодок такой же, как для группы колодок стандартных пониженной твердости.

4. При использовании на локомотивах тормозных колодок, смешанных по твердости, можно ожидать лучшие показатели экстренного торможения для экспериментальных колодок в диапазоне повышенных скоростей.

\section{Список литературы}

1. Красиков Г.В. Повышение ресурса чугунных тормозных колодок локомотива // Молодой ученый. 2011. - Т. 1, № 2. - C. 35-38.

2. Асташкевич Б.М. Повышение долговечности трущихся узлов транспортной техники методами комплексного упрочнения / МИИТ. - М., 1999. - 160 с.

3. Вуколов JI.А. Повышение работоспособности тормозных колодок подвижного состава железных дорог: дис. ... д-ра техн. наук. - М., 1988. - 428 с.

4. Буйносов А.П. Методы повышения ресурса колесных пар тягового подвижного состава: монография / ГОУ «УМЦ по образованию на железнодорожном транспорте». - М., 2010. - 244 с.

5. Буйносов А.П. Еще раз об износе колеса и рельса // Путь и путевое хозяйство. - 2010. - № 9. - С. 23-26.

6. Влияние состава и микроструктуры тормозных локомотивных колодок на трибологические свойства / А.А. Климов, А.В. Стручков, В.Б. Бондарик, В.П. Ильинский, С.В. Домнин, В.П. Кирпиченко // Вестник Иркутского государственного технического университета. 2017. - № 11. - С. 179-190.

7. Взаимодействие экспериментальных тормозных колодок, разработанных КрИЖТ ИрГУПС и бандажей колесных пар локомотивов: отчет о госбюджетной НИР (промежуточ.) / КрИЖТ ИрГУПС; рук. А.А. Климов; исполн.: Домнин С.В., Кирпиченко В.П., Бондарик В.Б. Красноярск, 2016. - 25 с. - Инв. № 115100710046.

8. Исследование возможности использования феррито-графитной микроструктуры для чугуна тормозной локомотивной колодки / А.А. Климов, С.В. Домнин, А.В. Стручков [и др.] // Научные перспективы XXI века. Достижения и перспективы нового столетия: материалы IX Междунар. науч.-практ. конф., Новосибирск, 13-14 марта 2015 г. Ч. 2. Технические науки. - 2015. - № 2(9). - С. 161-165.

9. Некоторые результаты массового обследования тормозных локомотивных колодок / А.А. Климов, С.В. Домнин, А.В. Стручков, Д.С. Хацкевич [и др.] // Системы. Методы. Технологии: науч. период. журн. 2015. - № 1. - С. 73-78.
10. Взаимодействие экспериментальных тормозных колодок, разработанных КрИЖТ ИрГУПС, и бандажей колесных пар локомотивов: (промежуточ.) / КрИЖТ ИрГУПС; рук. А.А. Климов; исполн.: Домнин С.В. Красноярск, 2013. - 58 с. - Инв. № 115100710046.

11. Климов А.А., Домнин С.В., Хацкевич Д.С. Способ повышения износостойкости тормозных локомотивных колодок из серого чугуна // Современные концепции научных исследований: IX Междунар. науч.практ. конф. - М., 2014. - Ч. 1. - С. 82-85.

12. Способ повышения износостойкости тормозных локомотивных колодок: пат. 2575505 Рос. Федерация / Стручков А.В., Денисов Р.А., Климов А.А., Хацкевич Д.С. - № 2014119180/02; заявл. 13.05.2014. опубл. 20.02.2016, Бюл. № 5 .

13. Фрикционный чугун для тормозных локомотивных колодок и способ его получения: пат. 2573848 Рос. Федерация, МПК C22C37/10, C21D 5/02 / Климов А.А., Стручков А.В. [и др.]; заявл. 24.07.2014; опубл. 27.01.2016, Бюл. № 3.

14. Исследование графитных включений в микроструктурах чугуна тормозных локомотивных колодок / А.А. Климов, А.В. Стручков, В.Б. Бондарик, В.П. Ильинский, С.В. Домнин, В.П. Кирпиченко // Вестник Пермского национального исследовательского политехнического университета. Машиностроение, материаловедение. - 2017. - Т. 19, № 3. - С . 19-33.

15. Способ улучшения трибологических характеристик пары «колесо-тормозная колодка» локомотивов / А.А. Климов, С.В. Домнин, А.В. Стручков [и др.] // Технические науки - от теории к практике: материалы VIII Междунар. конф. - СПб., 2016. C. $47-53$.

16. Исследование влияния структуры и твердости тормозных колодок на износ бандажей колес локомотивов / А.А. Климов, С.В. Домнин, А.В. Стручков, В.Б. Бондарик // Современные технологии, системный анализ, моделирование. - 2017. - № 1(53). - С. 215-218.

17. Исследование металлической основы микроструктуры тормозных локомотивных колодок / А.А. Климов, А.В. Стручков, В.Б. Бондарик [и др.] // Вестник института проблем естественных монополий. Техника железных дорог. - 2017. - № 4(40). - С. 26-30.

18. Влияние микроструктуры и твердости тормозной локомотивной колодки на трещинообразование чугуна / А.А. Климов, С.В. Домнин, А.В. Стручков [и др.] // Системы. Методы. Технологии: науч. период. журн. 2016. - № 2(30). - С. 64-68.

19. Металлографическое исследование процесса трещинообразования в чугуне тормозных локомотивных колодок / А.А. Климов, А.В. Стручков, В.Б. Бондарик [и др.] // Транспорт, транспортные сооружения, экология. - 2017. - № 3. - С. 94-106.

20. Климов А.А., Стручков А.В. Причины возникновения патологического износа бандажа в системе бандаж колеса локомотива-тормозная колодка и возможности его исключения // Вестник Пермского национального исследовательского политехнического университета. Машиностроение, материаловедение. - 2018. T. 20, № 3. - C. 5-11. 


\section{References}

1. Krasikov G.V. Povyshenie resursa chugunnykh tormoznykh kolodok lokomotiva [Increasing the service life of the cast iron brake pads of the locomotive]. Molodoi uchenyi, 2011, vol. 1, no. 2, pp. 35-38.

2. Astashkevich B.M. Povyshenie dolgovechnosti trushchikhsia uzlov transportnoi tekhniki metodami kompleksnogo uprochneniia [Increase of durability of rubbing units of transport equipment by methods of complex hardening]. MIIT. Moscow, 1999, 160 p.

3. Vukolov JI.A. Povyshenie rabotosposobnosti tormoznykh kolodok podvizhnogo sostava zheleznykh dorog [Increasing the efficiency of the brake pads of the railway rolling stock]. Doctor's degree dissertation. Moscow, 1988, $428 \mathrm{p}$.

4. Buinosov A.P. Metody povysheniia resursa kolesnykh par tiagovogo podvizhnogo sostava: monografiia [Методы повышения ресурса колесных пар тягового подвижного состава: монография]. GOU «UMTs po obrazovaniiu na zheleznodorozhnom transporte». Moscow, 2010, 244 p.

5. Buinosov A.P. Eshche raz ob iznose kolesa i rel'sa [One more time about the wear of the wheel and rail]. Put' $i$ putevoe khoziaistvo, 2010, no. 9, pp. 23-26.

6. Klimov A.A., Struchkov A.V., Bondarik V.B., Il'inskii V.P., Domnin S.V., Kirpichenko V.P. Vliianie sostava i mikrostruktury tormoznykh lokomotivnykh kolodok na tribologicheskie svoistva [Influence of composition and microstructure of brake pads on tribological properties]. Vestnik Irkutskogo gosudarstvennogo tekhnicheskogo universiteta, 2017, no. 11, pp. 179-190.

7. Vzaimodeistvie eksperimental'nykh tormoznykh kolodok, razrabotannykh KrIZhT IrGUPS i bandazhei kolesnykh par lokomotivov: otchet o gosbiudzhetnoi NIR (promezhutoch.) [Interaction of experimental brake pads developed by KrIZhT IrGUPS and tires of locomotive wheelsets:]. KrIZhT IrGUPS; ruk. A.A. Klimov; ispoln.: Domnin S.V., Kirpichenko V.P., Bondarik V.B. Krasnoiarsk, 2016, 25 p. Inv. no 115100710046.

8. Klimov A.A., Domnin S.V., Struchkov A.V. et al. Issledovanie vozmozhnosti ispol'zovaniia fer-rito-grafitnoi mikrostruktury dlia chuguna tormoznoi lokomotivnoi kolodki [Study of the possibility of using ferrite-graphite microstructure for cast iron brake pads]. Nauchnye perspektivy XXI veka. Dostizheniia i perspektivy novogo stoletiia: materialy IX Mezhdunarodnaia nauchno-prakticheskaia konferentsiia, part. 2. Tekhnicheskie nauki, 2015, no. 2(9), pp. 161-165.

9. Klimov A.A., Domnin S.V., Struchkov A.V., Khatskevich D.S. et al. Nekotorye rezul'taty massovogo obsledovaniia tormoznykh lokomotivnykh kolodok [Some of the results of the mass examination of brake pads]. Sistemy. Metody. Tekhnologii: nauchnyi periodicheskii zhurnal, 2015, no. 1 , pp. 73-78.

10. Vzaimodeistvie eksperimental'nykh tormoznykh kolodok, razrabotannykh KrIZhT IrGUPS, i bandazhei kolesnykh par lokomotivov (promezhutoch.) [Interaction of experimental brake pads developed by KrIZhT IrGUPS and tires of wheel sets of locomotives]. KrIZhT Ir-GUPS; ruk. A.A. Klimov; ispoln.: Domnin S.V. Krasnoiarsk, 2013, 58 p. Inv. no. 115100710046.
11. Klimov A.A., Domnin S.V., Khatskevich D.S. Spo-sob povysheniia iznosostoikosti tormoznykh lokomotivnykh kolodok iz serogo chuguna [A way to increase the wear resistance of grey cast iron brake pads]. Sovremennye kontseptsii nauchnykh issledovanii: IX Mezhdunarnaia nauchnoprakticheskaia konferentsiia. Moscow, 2014, part 1, pp. 82-85.

12. Struchkov A.V., Denisov R.A., Klimov A.A., Khatskevich D.S. Sposob povysheniia iznosostoikosti tormoznykh lokomotivnykh kolodok [Method to increase the wear resistance of brake pads]. Patent Rossiiskaia Federatsiia no. 2575505 (2016).

13. Klimov A.A., Struchkov A.V. et al. Friktsionnyi chugun dlia tormoznykh lokomotivnykh kolodok i sposob ego polucheniia [Friction cast iron for brake pads and how to obtain it]. Patent Rossiiskaia Federatsiia no. 2573848 (2016).

14. Klimov A.A., Struchkov A.V., Bondarik V.B., Il'inskii V.P., Domnin S.V., Kirpichenko V.P. Issledovanie grafitnykh vkliuchenii $\mathrm{v}$ mikro-strukturakh chuguna tormoznykh lokomotivnykh kolodok [Investigation of graphite inclusions in the microstructures of cast iron brake pads]. Vestnik Permskogo natsional'nogo issledovatel'skogo politekhnicheskogo universiteta. Mashinostroenie, materialovedenie, 2017, vol. 19, no. 3, pp . 19-33.

15. Klimov A.A., Domnin S.V., Struchkov A.V. et al. Sposob uluchsheniia tribologicheskikh kharakteristik pary «koleso-tormoznaia kolodka» lokomotivov [Method of improving tribological characteristics of the "wheel-brake pad" pair of locomotives]. Tekhnicheskie nauki - ot teorii k praktike: materialy VIII Mezhdunarodnoi konferentsii. SaintPetersburg, 2016, pp. 47-53.

16. Klimov A.A., Domnin S.V., Struchkov A.V., Bondarik V.B. Issledovanie vliianiia struktury i tverdosti tormoznykh kolodok na iznos bandazhei koles lokomotivov [Investigation of the influence of brake pad structure and hardness on the wear of locomotive wheel bandages]. Sovremennye tekhnologii, sistemnyi analiz, modelirovanie, 2017, no. 1(53), pp. 215-218.

17. Klimov A.A., Struchkov A.V., Bondarik V.B. et al. Issledovanie metallicheskoi osnovy mikro-struktury tormoznykh lokomotivnykh kolodok [Investigation of the metal basis of the microstructure of brake pads]. Vestnik in-stituta problem estestvennykh monopolii. Tekhnika zheleznykh dorog, 2017, no. 4(40), pp. 26-30.

18. Klimov A.A., Domnin S.V., Struchkov A.V. et al. Vliianie mikrostruktury i tverdosti tormoz-noi lokomotivnoi kolodki na treshchinoobrazovanie chugu-na [Influence of microstructure and brake pad hardness on cast iron crack formation]. Sistemy. Metody. Tekhnologii: nauchnyi period. Zhurnal, 2016, no. 2(30), pp. 64-68.

19. Klimov A.A., Struchkov A.V., Bondarik V.B et al. Metallograficheskoe issledovanie protsessa treshchinoobrazovaniia $\mathrm{v}$ chugune tormoznykh lokomotivnykh kolodok [Metallographic study of the process of cracking in cast iron of brake pads]. Transport, transportnye sooruzheniia, ekologiia, 2017, no. 3, pp. 94-106.

20. Klimov A.A., Struchkov A.V. Prichiny vozniknoveniia patologicheskogo iznosa bandazha v sisteme bandazh kolesa lokomotiva-tormoznaia kolodka i vozmozhnosti ego iskliucheniia [Causes of pathological bandage wear in the system locomotive-brake shoe wheel bandage and the possibility of its exclusion]. Vestnik Permskogo natsional'no- 
go issledovatel'skogo politekhnicheskogo universiteta. Mashinostroenie, materialovedenie, 2018, vol. 20, no. 3, pp. 5-11.

\section{Получено 06.11.18}

Опубликовано 21.03.19

\section{Сведения об авторах}

Климов Анатолий Александрович (Красноярск, Россия) - кандидат технических наук, доцент кафедры эксплуатации железных дорог Красноярского института железнодорожного транспорта, филиала Иркутского государственного университета путей сообщения; e-mail: anatoly.klimoff2013@yandex.ru.

Стручков Алексей Валентинович (Красноярск, Россия) - кандидат технических наук, доцент кафедры основ конструирования машин Сибирского государственного аэрокосмического университета им. акад. М.Ф. Решетнева; e-mail: str-alex-v@mail.ru.

\section{About the authors}

Anatoly A. Klimov (Krasnoyarsk, Russian Federation) - Ph.D. in Technical Sciences, Associate Professor, Department of Operation of Railways, Krasnoyarsk Institute of Railway Transport, Branch of Irkutsk State Transport University; e-mail: anatoly.klimoff2013@yandex.ru.

Alexey V. Struchkov (Krasnoyarsk, Russian Federation) - Ph.D. in Technical Sciences, Associate Professor, Department of Machine Design Basics, Siberian State Aerospace University named after academician M.F. Reshetnev; e-mail: str-alex-v@mail.ru. 